\title{
VIDA E TRABALHO NO TEMPO DAS MINAS: A TRAJETÓRIA OPERÁRIA DE MANOEL JOVER TELES
}

\section{- ÉDER DA SILVA SILVEIRA}

Universidade de Santa Cruz do Sul

RESUMO O presente artigo é um recorte adaptado de uma pesquisa maior realizada pelo autor e que resultou em uma biografia histórica de Manoel Jover Teles, o "Manolo" (1920-2007). Trata-se de um personagem polêmico na história do movimento e da dissidência comunista no Brasil, pois foi importante liderança dentro do PCB e do PCdoB, e esteve envolvido no episódio conhecido como o "Massacre da Lapa", em 1976. O texto limita-se ao período em que Manolo foi operário nas minas de carvão de São Jerônimo, privilegiando dados referentes à sua família e juventude. De natureza qualitativa, o percurso metodológico está baseado em uma interpretação de dados oriundos de entrevistas realizadas pelo autor e, também, da análise de documentos. A análise está ancorada em elementos da abordagem da Biografia Histórica (LE GOFF, 1989) e na mediação entre o vivido e o narrado (GINZBURG, 2007; CERTEAU, 2008). Busca-se compreender aspectos relativos ao trabalho e à política nas minas de carvão de São Jerônimo/RS, nas décadas de 1930 e 1940, a partir de alguns fios e rastros de caráter (auto)biográfico sobre esse indivíduo e sua trajetória enquanto operário, procurando apreender as inteligibilidades de suas experiências em contextos nos quais foi operário e deputado estadual pelo PCB.

Palavras-chave: Biografia. Trabalho. Mineração de carvão no Rio Grande do Sul.

\section{ABSTRACT LIFE AND WORK IN THE MINES: THE WORKING TRAJECTORY OF MANOEL JOVER TELES}

This article is adapted from a cutout of the chapters of doctoral research that resulted in a historical biography of Manoel Jover Teles, known as "Manolo" (1920-2007). This is a controversial figure in the history of the movement and dissidence comunist in Brazil, because it was an important leadership within the PCB and PCdoB, and was involved in the episode that became known as the "Massacre of Lapa" in 1976. The text is limited to the period in which Manolo worked in 
the coal mines of São Jerônimo, favoring data relating to his family and his youth. Of qualitative nature, the methodological course is based on an interpretation of data from interviews conducted by the author and also from the analysis of documents. The analysis is anchored in elements of the approach of Historical Biography (LE GOFF, 1989) and in the mediation between lived and narrated (GINZBURG, 2007; CERTEAU, 2008). It seeks to understand aspects of work and politics in the coal mines of São Jerônimo-RS, in the 1930s and 1940s, from some wires and biographical traces of that individual and his career as a worker, seeking to apprehend the intelligibilities of his experiences in contexts as worker and state representative by the PCB.

Keywords: Biography, workforce, Coal mine working in Rio Grande do Sul. TRAJETORÍA OPERARIA DE MANOEL JOVER TELES

Este artículo es un recorte adaptado de una investigación más grande llevada a cabo por el autor y dio lugar a una biografía histórica de Manoel Jover teles, el "Manolo" (1920-2007). Es un personaje controvertido en la historia del movimiento y la disidencia comunista en Brasil, porque fue un liderazgo importante dentro del PCB y el PCdoB, y participó en el episodio conocido como la "masacre de Lapa" en 1976. El texto se limita al período en el que Manolo trabajaba en las minas de carbón de San Jerónimo, favoreciendo los datos relativos a su familia y juventud. De carácter cualitativo, la vía metodológica se basa en una interpretación de los datos de las entrevistas realizadas por el autor y también en el análisis de documentos. El análisis se ancla en los elementos del acercamiento la biografia histórica (LE GOFF, 1989) y la mediación entre el vivido y el narrado (GINZBURG, 2007; CERTEAU, 2008). Busca comprender aspectos relacionados con el trabajo y la política en las minas de carbón de San Jerónimo-RS, en los años 1930 y 1940, desde algunos filamentos y trazas de carácter (auto) biográficos sobre este individuo y su trayectoria como trabajador, buscando aprehender la inteligibilidad de sus experiencias en contextos en los que fue un trabajador y representante de PCB.

Palabras clave: Biografía. Trabajo. Minería de carbón en Rio Grande do Sul. 


\section{Em busca de Manolo: aspectos introdutórios}

\begin{abstract}
"[...] Vislumbro as altas torres de madeira sustentando polias, por onde deslizam os cabos de aço das gáveas de ferro, encimando escuros poços, de boca aberta, engolindo gente para o centro da terra, expelindo hulha sobre a superficie, no movimentar das gaiolas. Ouço ruídos da labuta de homens e crianças tisnados de carvão, desbravando as entranhas da terra [...] o âmago da terra feito de colmeia de negros favos. [...] Ouço o metralhar das máquinas cortadoras, ferindo o carvão de pedra. 0 ronco dos marteletes, furando a rocha; [...] envolvendo tudo e a todos em negra nuvem de pó; $E$ mineiros internando-se em todas as direções, ocupando seus postos de trabalho. [...] Manolo". (TELES, 1993, s.p.)
\end{abstract}

Manoel Jover Teles, o "Manolo", nasceu na cidade de São Manuel, em São Paulo, em 28 de julho de 1920. Seu Pai, Jeronymo Jover, e sua mãe, Mathilde Telles, eram espanhóis. Uma sintese biográfica publicada no periódico $\mathrm{Li}$ bertação, na ocasião da campanha eleitoral do PCB de 1945 para o Legislativo Federal, informa que Manoel Jover Teles descendia de "uma família de mineiros", e que:

seus avós e seus pais nunca tiveram outra profissão. Seu pai, Jerônimo Jover Ocaña, ganhava a vida na mina de Linares, província de Jaen, na Espanha. Velho lutador operário, foi obrigado a emigrar por motivos políticos. E o velho mineiro fugido da reação brutal dos latifundiários ibéricos soube educar seus filhos na escola da luta e da solidariedade proletária. (QUEM..., 1945, p. 3-6)

Jover tinha cinco irmãos e duas irmãs: Bráulio, Julião, "Nêne", Antônio, Leon, Adélia e Gregória. "Nêne" era o apelido de "Jerônimo Jover Telles", conforme texto publicado no jornal Nossa Folha, sobre a história do município paulista de "Cerquilho", local onde a família de Jover se fixou quando chegou da Espanha e onde havia uma mina de carvão (MUNICÍPIO..., 2013, s.p.).
Iracema, filha de Manoel Jover Teles, lembra que o tio Julião Jover Telles "morreu por causa da mina, com o pulmão cheio de carvão" - motivo que também explicaria a morte de Leon. Sobre o tio Antônio, Iracema lembra-se de Manolo contar que "ele trabalhou um pouco nas minas e depois saiu para o mundo, e que seu corpo está enterrado em São Paulo" (LIMA, l., 2009, s.p.).

As fontes são insuficientes para recuperar com nitidez o como, o quando e o porquê da emigração da família de Manoel Jover Teles. O texto publicado pelo Libertação, em 1945, salienta que seu pai fora um "velho lutador operário", mineiro, no município de Linares, província de Jaén, na Espanha. Diz ainda que "foi obrigado a emigrar por motivos políticos". É possível, como publicou o periódico, que Jeronymo tenha sido um operário militante no espaço da(s) mina(s) de carvão daquela região, a Andaluzia.

Na Espanha, "o anarquismo surgiu com os operários de Barcelona, espalhando-se rapidamente entre os camponeses sem terras de Andaluzia e Valência" (WOODCOCK, 1981, p. 42). No final da primeira década do século XX, Linares apresentava sinais de uma efervescência sindicalista e anarquista e não eram raras a publicação e a difusão de folhetos anarquistas (SORIANO; MADRID, 2010). Linares foi o "epicentro" do setor mineiro de Jaén no final do século XIX, e talvez não por acaso, em 1900, foi criada, nessa cidade, a Federación de Sociedades Obreras de Resistencia que "se daria bajo a los auspicios socialistas" e contaria, em 1915, com três mil afiliados (EGEA BRUNO, 1991, p. 137-153).

Entre o final do século XIX e início do século $\mathrm{XX}$, os mineiros de Linares padeceram com uma crise econômica e a ausência de regulamentações trabalhistas. A crise trouxe-lhes o desemprego e o aumento das condições precárias de trabalho, com jornadas laborais cada 
vez mais abusivas, além de problemas com alimentação, posse de terra e moradia. Não é impossivel que, naquele contexto, portanto, o pai de Manoel Jover Teles tenha exercido alguma militância na luta por condições mais dignas de sobrevivência e por isso tenha tido problemas para continuar em Linares. É preciso relativizar, todavia, quando o texto do Libertação diz que Jeronymo foi "obrigado a emigrar por motivos políticos". Para lembrar Michel de Certeau, parece notório que aquele texto jornalístico de propaganda de 1945, publicado no contexto das campanhas eleitorais, tenha se constituído a partir de algumas "operações que regularam sua escrita" (CERTEAU, 2008). Existe um esforço para a "fabricação de um objeto" (Jover Teles, o candidato ideal dos comunistas) que, simultaneamente, ocorre através da "ocultação/deturpação do sentido" (o pai emigra apenas por motivos políticos) e da ênfase na mensagem da ascendência operária/ militante. Essas operações da escrita, percebidas na leitura do Libertação sobre a biografia de Jover Teles, imputavam-lhe certas qualidades e condições para a materialização do "candidato ideal" naquele contexto de campanha do PCB à Câmara Federal. A rigor, o contexto econômico de Linares, sobretudo para os mineiros de Jaén, permite inferir que o motivo da emigração da família de Jover Teles não pode ser explicado apenas pelo viés da perseguição política. O Informe de um engenheiro chefe das minas de Linares, datado de 5 de dezembro de 1883, já apontava, por exemplo, que “las grandes crisis se han resuelto con la emigración" (EGEA BRUNO, 1991, p. 148). Referindo-se a Manoel Jover Teles, o periódico Libertação publicou, em 1945, que "em 1921 sua família veio para o Rio Grande do Sul, em viagem di-

1 Nessas eleições, realizadas em 02 de dezembro de 1945 - para presidente da República, Senado e Câmara Federal - Manoel Jover Teles obteve 1.206 votos para deputado federal, ficando como sétimo suplente do PCB. (AS ELEIÇÕES..., s.d., p. 254) reta para as minas de carvão de São Jerônimo [...]", região onde hoje é o município de Arroio dos Ratos/RS (QUEM..., 1945, p. 3).

\section{Vida e trabalho no tempo das minas}

Quando Jover Teles e família chegaram a Arroio dos Ratos, em 1921, o local ainda era distrito ou "vila" de São Jerônimo. Sua emancipação ocorreu em 1964, e sua história está diretamente ligada à extração de carvão. Nos relatórios dos presidentes da Província, no final da primeira metade do século XIX, consta que já havia notícias da existência de carvão mineral no solo de São Jerônimo em data anterior a 1850 (SILVEIRA, 2000). Independente da discussão sobre o local exato em que foi descoberta a primeira jazida, foi à margem esquerda do Arroio dos Ratos, na Serra do Herval, que a indústria carbonífera se desenvolveu com a chegada do inglês James Johnson. Em 1853 ele foi incumbido pelo Presidente da Província, João Lins Vieira Cansanção de Sinimbu, de explorar e testar o carvão da região. o carvão foi muito utilizado durante as Primeira e Segunda Guerras Mundiais, tanto no Brasil quanto na Europa, devido à escassez de carvão e petróleo em nivel internacional. Quando Manolo chegou às "Minas dos Ratos" a região vivia um período de pico de produção devido ao contexto da Primeira Grande Guerra.

Conforme informações pesquisadas no jornal Correio do Povo, no ano de 1953, a exploração do carvão na região de São Jerônimo ficou a cargo de mais de uma empresa até que Manoel Jover Teles começasse a trabalhar nas minas, no início dos anos de 1930. Em 1866, o inglês James Johnson conseguiu do Governo Imperial o direito de explorar carvão na mina descoberta, na localidade de Arroio dos Ratos, então pertencente a São Jerônimo. Com os privilégios recebidos, Johnson voltou para o seu 
país e conseguiu capital e mineiros profissionais. Regressou a São Jerônimo trazendo consigo doze famílias inglesas mineiras. Em 1872, D. Pedro II concedeu a "The Imperial Brazilian Collieries Comp. Limited" (empresa carbonífera "do Arroio dos Ratos" constituída em Londres, 1871, sociedade organizada com capitais ingleses, por James Johnson) autorização para funcionar. Assim, a exploração de carvão em São Jerônimo entrou na fase real de trabalho. Para a eficiência do transporte, a Brazilian Collieres, em 1873, construiu uma Via Férrea das Minas do Arroio dos Ratos à Vila de São Jerônimo, com ponto terminal no denominado "Porto do Carvão", "Porto Velho", à margem do rio Jacuí. Contudo, o andamento comercial da empresa declinava. James Johnson retirouse da direção da empresa que, em 1875, passou às mãos do novo gerente, William Tweede, também inglês. A mineração tomou alguns ares por mais algum tempo, mas Tweede não conseguiu fixar o equilíbrio da empresa e esta faliu, sendo seu acervo vendido em 1880. Uma firma comercial de Porto Alegre, que já havia trabalhado com mineração, sendo concessionária desde 1878, lavrou e arrematou o acervo da empresa fundada por Johnson. Assim, nesse ano, a firma denominada Holtzwersig e Cia. passou a adquirir o direito de exploração. Essa empresa floresceu, mas em 1883 houve nova mudança. Uma nova empresa de capitais nacionais, a Cia. Minas de Carvão do Arroio dos Ratos, substituiu a Holtzwersig e Cia. Em 1889, essa Companhia foi à liquidação judicial (SILVEIRA, 2008).

Nesse mesmo ano, uma nova firma surgiu: a Cia Estrada de Ferro e Minas de São Jerônimo, com sede no Rio de Janeiro. Cristina Ennes da Silva, que realizou um estudo aprofundado sobre as Companhias de mineração em seu doutoramento, salienta que, "nas primeiras décadas do século XX", encontrou "registros da atuação de três companhias de mineração na região". Segundo essa autora, essas empresas "diferiam em suas razões sociais e terreno de extração", todavia, ao analisar "o corpo acionista de cada uma delas", a autora observou "a presença das mesmas pessoas, as quais se alternavam temporalmente entre os cargos das empresas" (SILVA, 2007, p.153). Quando Manolo começou a trabalhar como mineiro, na década de 1930, ocorreu a fusão das empresas “Cia. Estrada de Ferro e Minas de São Jerônimo" e da "Cia. Carbonífera do Butiá", surgindo o CADEM - Consórcio Administrador de Empresas de Mineração. A partir daí o CADEM administrou o complexo da mineração de carvão em São Jerônimo e em Butiá. Em Arroio dos Ratos, à época distrito de São Jerônimo, hospital, escolas, telefones, água, luz, terras etc., eram propriedades do CADEM, situação que, segundo Sulzbach, "levou o minerador a uma dependência generalizada pela Cia. Mineradora" (SULZBACH, 1989, p.18). A habitação da família de Jover Teles, não diferente da maioria esmagadora dos mineiros, também pertencia ao CADEM, alvo das críticas quando Jover Teles iniciou sua militância política.

Durante sua infância e juventude, Manolo viveu com sua família em uma casa "de madeira" e "alvenaria", “cedida", "de aluguel", no estilo do que nomeavam "república", característica comum em relação às habitações dos mineiros na Região Carbonífera do Rio Grande do Sul.

Sobre a moradia, à época em que foi mineiro, Manolo denunciou à Tribuna Popular:

Os mineiros vivem completamente desamparados, com salários os mais baixos que se possa imaginar. Habitam casas de madeiras ou pequenos ranchos, aos bandos, como se fossem animais, havendo casos de morarem 16 pessoas nesses ranchos. Na maioria das vezes moram duas ou três famílias em cada casa, porquanto não há dinheiro para se darem ao luxo de ter cada uma a sua residência. Muitas casas são construídas pelos mineiros que se tornam as- 
sim seus proprietários. Entretanto o terreno é da Companhia e com a saída dos trabalhadores as casas passam à propriedade daquela. (TELES, 1946, p. 1)

Cornelia Eckert, em sua dissertação intitulada Os homens da mina, ao se referir à modalidade de habitação de Arroio dos Ratos salientou que esta não se diferenciava das vilas operárias de fábricas e minas que, conforme Eva Blay (apud ECKERT, 1985, p. 8), caracterizou-se como uma das primeiras soluções coletivas encontradas pelos patrões no contexto da emergência da indústria capitalista. As "casas geminadas que formavam uma longa fileira", ao longo das ruas, faziam parte de um sistema de controle que, não raro, exercia papel imobilizador do operário através da moradia.

A Companhia fornece casas aos mineiros cujo aluguel é descontado no salário. o controle ideológico que ela mantém sobre a expansão da vila operária estende-se sobre outros domínios do cotidiano dos mineiros e de suas famílias. A Companhia constrói a Igreja Católica, o hospital, a escola e mantém a venda (mercearia) [...]. Trata-se de uma relação totalizante com a Empresa, a qual domina esta relação não só na esfera do trabalho, mas também na condição de habitação, de tempo livre e de lazer do mineiro, de educação, e da religião. (ECKERT, 1985, p. 8)

As informações obtidas nas entrevistas realizadas com alguns familiares corroboram a informação dada por Manoel Jover Teles no questionário respondido por ele, disponivel no Museu Estadual do Carvão, sobre vários aspectos. $^{2}$ Um deles diz respeito ao início de suas atividades como mineiro. Segundo essas fontes, ele começou a trabalhar aos onze anos

2 Trata-se de um questionário produzido pelo Museu Estadual do Carvão, que integrava um projeto dessa instituição no ano de 1997, intitulado "Memória Mineira". Diversos mineiros responderam a esse questionário, que tinha como objetivo registrar memórias de ex-operários do município de Arroio dos Ratos sobre o trabalho nas minas de carvão e, consequentemente, do espaço onde hoje funciona o Museu. de idade, em 1931, no Poço Um de Arroio dos Ratos, nas funções de guincheiro, cartucheiro e furador, as quais serão explicadas no decorrer deste artigo.

O local denominado Poço Um, no município de Arroio dos Ratos, abrange o espaço onde atualmente funciona o Museu Estadual do Carvão. Ambiente peculiar no complexo da mineração de carvão do Estado, o Poço Um abrigou uma variada gama de funções e atividades de mineração, tanto na superficie quanto no subsolo, e também o local onde funcionou a primeira Usina Termelétrica do Brasil. Quando Jover Teles começou a trabalhar no Poço Um vislumbrou "as altas torres de madeira", os "escuros poços de boca aberta, engolindo gente para o centro da terra", viu "uma legião de homens marchando pelos caminhos, parecendo pirilampos pelo balanço dos lampiões de acetileno fazendo piscar a chama ao vento" (TELES, 1993, s.p.). Nesse local, possivel de se perder um garoto de onze anos, funcionavam, dentre outras coisas: as caldeiras da usina que produziam energia elétrica para a cidade e municípios vizinhos; as oficinas onde eram construídas as ferramentas e as vagonetas para o trabalho; a madeireira; o carregamento e o transporte de carvão através de "Maria-fumaça"; e o prédio administrativo da Cia. Mineradora.

Isabel Gonçalves, última companheira de Jover, salientou: "o pai e os irmãos de Manolo até nem queriam que ele trabalhasse", mas devido às insistências do jovem que "queria trabalhar fora como o pai e os irmãos", "com onze anos ele desceu pra baixo da mina" (GONÇALVES, 2011, s.p.). Quando Manolo começou a trabalhar nas minas, os acidentes de trabalho eram muito frequentes. Em 1931, ano provável de seu ingresso no subsolo como ajudante de seu pai, as notícias de acidentes ventilavam nas galerias, talvez até mais do que o próprio oxigênio que havia para os mineiros respira- 
rem, conforme fontes encontradas no Arquivo Público do Estado do Rio Grande do Sul. Acidentes com crianças e adolescentes também eram comuns. Em 1929, por exemplo, ainda continuava em trâmite um processo contra a Cia. de Ferro e Minas de São Jerônimo, movido pelo operário Carlos Wietzorecki, pela morte de seu filho Otto, um menor de 14 anos que faleceu ao sofrer um acidente em serviço da empresa (ESTADO DO RIO GRANDE DO SUL, 1929). As cenas de acidentes geralmente fazem parte das memórias dos operários. ${ }^{3}$ Talvez, por isso, o pai de Manolo tenha ficado reticente quanto ao ingresso do filho, ainda tão jovem, em um espaço de trabalho tão periculoso. Leon Jover Teles, um dos irmãos de Manolo, começou a trabalhar na mina em 1928, com 13 anos de idade, no mesmo ano em que morreu o garoto Otto.

De acordo com o processo $1.734 / 42$, do Tribunal de Apelação do Estado do Rio Grande do Sul, em 1942, Leon estava com 26 anos quando moveu um processo judicial contra a Cia. Mineradora, solicitando uma indenização de "dez contos e oitocentos", por "ter contraído a moléstia profissional do mineiro, antracose, que o tornou total e permanentemente incapaz para qualquer trabalho". A doença e a situação de incapaz foram confirmadas em laudo médico anexado ao processo, e as radiografias dos pulmões do jovem mineiro. A Cia. Estrada de Ferro e Minas de São Jerônimo, ré no processo de autoria de Leon Jover Teles, apresentou sua defesa alegando que os males de que se queixava o autor da ação não constituíam doença profissional e que, por este motivo, não lhe cabia o direito de exigir indenização da empresa. A Cia. considerou o laudo médico "deficiente" e exigiu que Leon fosse submetido à nova perícia técnica por um dos "médicos especializados em medicina legal" do Estado. Para isso, a

3 Ver: Klovan (2009), Silveira (2008), Silva (2007), Cioccari (2004) e Speranza (2012), dentre outros. empresa se propôs a assumir todas as despesas que fossem necessárias para a realização dos novos exames, e também em relação ao transporte e à hospedagem do operário (ESTADO DO RIO GRANDE DO SUL, 1942).

Outro irmão de Manolo, Braulio Jover Telles, entrou com processo na Justiça, em outubro de 1946, contra a mesma Cia. Mineradora. Ele também trabalhava no subsolo como furador, e por ter se recusado a trabalhar em um domingo recebeu suspensão por três dias. Empregado desde 1932, Braulio entrou na Justiça, requerendo o pagamento dos dias de suspensão. No processo, alegou ter pedido à empresa para trabalhar sábado à noite e que a mesma não permitiu. Segundo a versão de Braulio, contida nos autos, o capataz teria the perguntado se sua falta tinha alguma "relação com política". Braulio disse ter respondido não decorrer de política, "mas unicamente de uma questão íntima" (ESTADO DO RIO GRANDE DO SUL, 1946). Dentre os argumentos do operário estava a necessidade de visitar a filha e outros dois filhos doentes em um hospital. A pergunta do capataz é mais bem compreendida em uma passagem da tese de Clarice Speranza, quando a autora realiza uma análise quantitativa das ações impetradas pelos operários da mineração na Justiça do Trabalho de São Jerônimo, entre 1946 e 1954:

o número de resultados totalmente favoráveis aos trabalhadores da mineração na Justiça do Trabalho foi significativamente maior em 1949 e em 1951. O fenômeno se deve, em 1949, aos diversos processos plúrimos impetrados pelo Sindicato e pelos trabalhadores para o cumprimento da Lei 605 . Em 1951, a porcentagem de vitórias também sobe devido a processos coletivos, impetrados por 202 mineiros, desta vez para o pagamento de um domingo nãotrabalhado devido às eleições (a Companhia Carbonífera do Butiá condicionou a folga dada no dia do pleito à jornada compulsória no domingo posterior; quem não trabalhou, perdeu o descanso semanal remunerado e também a 
gratificação por frequência). (SPERANZA, 2012, p. 101-102)

Em 28 de novembro do mesmo ano, a Justiça cancelou a suspensão de Braulio e condenou a empresa a pagar o valor referente aos dias suspensos, acrescendo as custas do processo.

Em 1947, após Manoel Jover Teles assumir uma vaga de suplente como deputado estadual do PCB na Assembleia Legislativa do Estado do Rio Grande do Sul, o tema da regulamentação do dispositivo constitucional que concedia o pagamento dos dias de trabalho de feriados e domingos foi um dos temas de sua reivindicação no plenário. Em 16 de setembro daquele ano, por exemplo, Jover discursou na Assembleia Legislativa solicitando a aprovação da indicação que pedia imediata regulamentação do dispositivo constitucional que concedia o pagamento dos dias feriados e domingos aos operários.

Em 1993, em palestra proferida na Câmara de Vereadores de Arroio dos Ratos, Jover Teles salientou:

Como a maioria dos meninos, filhos de mineiros, também eu desci à profundidade da mina (poço 1) aos onze anos de idade, para trabalhar como cartucheiro na galeria do Luiz Gago, mister que consistia em fazer-me, nessa idade, lidar com pólvora, dinamite, espoletas, papel de cartucho, estopim, etc. Até a idade de 24 anos, além de cartucheiro, exerci as seguintes atividades: Cortador, Furador, Guincheiro, Tocador de Carros, Madeireiro, etc. (TELES, 1993, s.p.)

Sobre os cargos que Manolo desempenhou no Poço Um, eram, quase sem exceção, trabalhos realizados no subsolo. De todas as funções desenvolvidas nos subterrâneos das minas de carvão, a de "Furador" foi a principal, também desempenhada por seu pai e seus irmãos. Sua filha Iracema lembra-se das explicações do pai sobre a função: "ele usava aquela britadeira de ombro, perfurava para tirar o carvão. Tanto é que ele ficou surdo do ouvido esquerdo devido a este trabalho que ele fazia". Em entrevista concedida ao jornal Tribuna Popular, em 1946, Manoel Jover Teles (1946, p. 1) destacou:

Como operário especializado que é, Manoel Teles dá-nos agora detalhes esclarecedores sobre o trabalho na mina. Ele é furador, isto é, o operário que com uma perfuratriz, desloca os grandes blocos de carvão. É ele quem fala:- ‘O furador é o mais bem pago da mina. Tem um salário fixo de 19 cruzeiros e cinqüenta centavos por dia e uma porcentagem de 8 cruzeiros e cinqüenta centavos sobre cada tonelada de carvão que desloca. É uma espécie de 'semi -empreitada" [...].

A infância no tempo das minas parece ter sido, no mínimo, amarga ao menino Manolo. Órfão de mãe aos seis anos de idade, ele começou a laborar ainda cedo nas profundezas das galerias de carvão. Pouco antes de completar 27 anos, proferindo o mais longo de seus discursos como deputado estadual na Assembleia Legislativa, Manolo fez diversas denúncias contra o CADEM, ao defender a encampação das minas de carvão pelo governo gaúcho:

0 ambiente de trabalho em que vivem os mineiros é dos piores possiveis. Trabalha o mineiro num ambiente de completa insalubridade. [...] Os próprios contratos de trabalho usados pelo CADEM são contratos que lesam, de fato, a dignidade e não permitem ao mineiro subsistir ao rude trabalho por espaço máximo de 10 a 15 anos. [...] Podemos afirmar que em parte nenhuma do nosso país existe uma empresa que tenha a coragem de ridicularizar as nossas leis, burlando-as em quase todo seu conteúdo, como o famigerado CADEM. Ainda há pouco tempo atrás, os próprios mineiros, que, como sabemos, trabalham na escuridão completa, que necessitam, portanto, de um lampião de acetileno, ainda há pouco tempo, dizia, os próprios mineiros compravam esse acetileno com seus parcos salários. [...] Ainda há mais. A alpercata é um calçado especial que se usa nas minas e só com eles é possivel trabalhar. Pois bem, a Consolidação das Leis de Trabalho man- 
da que a empresa forneça esse calçado adequado a natureza especial do serviço, mas essa alpercata é comprada pelos próprios mineiros. Também a Consolidação das Leis do Trabalho diz que toda empresa onde exista mais de 300 operários fica obrigada a manter refeitório para seus operários. No CADEM não existe nada disso. [...] Foi tendo em vista esses problemas que o meu Partido, o glorioso Partido Comunista do Brasil, incluiu no seu programa mínimo um ponto que diz respeito à encampação das minas de São Jerônimo. Quais seriam os beneficios que tiraria o povo da encampação? Em primeiro lugar alegar-se-ia: "Onde buscar dinheiro essa encampação?" Responderia eu: Vamos encampá-las pelo custo histórico, porque os próprios diretores do CADEM nunca se furtaram a dizer que, se faziam cinemas, se construíam praças, se calçavam ruas, era para empregar os lucros extraordinários e não pagar o imposto ao Governo. Quer dizer que muita coisa que existe na superfície é do próprio Governo. (ESTADO DO RIO GRANDE DO SUL, 1947, p. 405-407)

O referido discurso de Jover Teles é um dos principais textos deixado por ele sobre sua experiência como operário nas minas de carvão. De início, ele comenta que desde que entrou naquele parlamento planejava falar sobre as condições de trabalho nas minas de São Jerônimo. Esclareceu que a "motivação para o discurso" foi uma matéria lida no jornal Correio do Povo, naquele mês de junho de 1947, a respeito de um "projeto de decreto-lei de importação de carvão estrangeiro". Jover problematizou a notícia, especialmente o discurso do CADEM sobre a "baixa produção das minas de São Jerônimo". Ele recorda ao parlamento um decreto de agosto de 1946, no qual o Governo Federal concedeu “isenção de direitos de importação e das demais taxas aduaneiras para o carvão que fosse adquirido pela Viação Férrea para o seu consumo" durante aquele ano. No mesmo discurso, criticou reportagens da mídia sobre o CADEM ("matérias pagas que escondem arbitrariedades"), e sugeriu esquemas de corrupção e de controle por parte das Compa- nhias de Mineração que integravam o CADEM. Citou, por exemplo, o caso de uma impetração de dissídio coletivo pelo Sindicato dos Mineiros na Justiça do Trabalho, em 1946, ocasião em que um representante desse Ministério realizou uma visita às minas, e após escrever parecer favorável aos mineiros em determinado relatório acabou sendo exonerado de seu cargo. Manolo também descortinou o esquema de trabalho "por empreitada", ao qual eram submetidos muitos cargos do subsolo:

Através dessas reportagens, o CADEM esconde todas as arbitrariedades que comete naquele feudo, que são as minas de São Jerônimo. Diz que um furador ganha $\mathrm{Cr} \$ 8,50$ por tonelada de carvão e que tira de 17 a 20 toneladas diárias, e que, portanto, faz um grande ordenado por dia. Mas Sr. Presidente, e ilustres Representantes do Povo, o que o CADEM não diz nas suas reportagens é o seguinte: que de fato um furador que trabalha por empreitada tira $\mathrm{Cr} \$ 8,50$ por uma tonelada de carvão, mas que desses $\mathrm{Cr} \$ 8,50$, o furador paga para o tocador de carros $\mathrm{Cr} \$ 3,50$ (três cruzeiros e cinqüenta centavos) por tonelada, e Cr\$1,20 por quilo de pólvora, Cr\$ 0,13 por pé de estopim; Cr\$25,00 pelo quilo de dinamite, $\mathrm{Cr} \$ 3,60$ pelo quilo de papel, $\mathrm{Cr} \$ 18,00$ como diária de seu cartucheiro, e Cr\$20,00 para seu encarregado e que no fim das contas, quando um furador tira 400 ou 500 toneladas durante $o$ mês, em virtude dessa empreitada ilusória, por cada tonelada de carvão fica para si uma média de apenas $\mathrm{Cr} \$ 1,20$, e um furador que deu todo seu esforço no sentido do progresso da Pátria, ele que tudo fez para criar condições ao desenvolvimento industrial de nosso povo, não raro ganha $\mathrm{Cr} \$ 500,00$ ou $\mathrm{Cr} \$ 600,00$ pelo mês de trabalho. (ESTADO DO RIO GRANDE DO SUL, 1947, p. 405-407)

O discurso de Jover Teles, em 1947, parece conter detalhes que, talvez, só mesmo um operário que trabalhou nas funções citadas pudesse realizar. De acordo com os textos deixados por Manolo, ele teria tido diferentes cargos nas minas de carvão, em que os principais citados foram os de "cartucheiro" e "furador", 
os quais receberam destaque em seu discurso na Assembleia Legislativa gaúcha e na Câmara de Vereadores de Arroio dos Ratos, em 1947 e 1993, respectivamente. No questionário respondido por ele, disponível no Museu Estadual do Carvão, na década de 1990, ratificou que trabalhou nas minas como "cartucheiro" e "guincheiro", ascendendo aos cargos de "furador", "cortador" e "patrão de galeria" entre os anos 1938 e 1939, após ter completado 18 anos.

O trabalho como "guincheiro" consistia em manejar o "guincho", instrumento que ficava na superficie e que controlava as descidas e subidas da "gaiola", elevador que dava acesso ao subsolo e pelo qual também se transportava madeira e carvão. "Havia muito companheirismo, era um ambiente agradável e não precisava fazer muito esforço", disse Jover Teles sobre esta função (ESTADO DO RIO GRANDE DO SUL, 1997a, p. 2).

No final dos anos 1930, já com seus 18 anos, Manolo passaria a trabalhar no subsolo como "cartucheiro" e "furador". Sobre o cargo de furador, ele registrou também que se tratava de um dos cargos de maior remuneração no subsolo: "trabalho muito perigoso", com o qual se conseguia "ganhar mais", destacou Jover. Conforme esclareceu Clarice Speranza, "geralmente o furador era também o patrão da galeria." A função, relata a autora, era desempenhada por "mineiros mais experientes e com maior conhecimento técnico, eles coordenavam o trabalho das equipes responsáveis pela extração [...]" (SPERANZA, 2012, p. 53). O "furador" fazia furos com "cortadeiras e marteletes" nas paredes de pedra, e o "cartucheiro" o acompanhava preparando e depositando os cartuchos, algumas vezes chamados de "canudos", que serviam para explodir e fazer desmoronar o "ouro negro". De acordo com Paulo Junqueira Gomes, ex-mineiro da região, o "estopim deveria ser aceso pelo furador, que era o principal responsável" (GOMES, 2013, s.p.).
Certamente foi nas minas que o apelido "Manolo" ficou consolidado, pois eram comuns os apelidos entre os mineiros. "Praticamente todos os mineiros tinham apelidos" (SILVEIRA, 2000 , s.p.). Até mesmo os animais que faziam o trabalho no subsolo tinham apelidos.

No subsolo tinha cocheiras para os burros. 0 burreiro colocava os freios e os balainhos no burro. 0 burro puxava cinco carros vazios e três carros cheios. Ele fazia o trabalho do maquinista até a estação, e da estação até o maquinista. [...] No subsolo tinha dois burros, o Macaco e o Dorado. 0 burro quando completava oito horas de trabalho, empacava. Enquanto trabalhava um burro, o outro descansava. Os burros subiam na superficie nos domingos. Para subir, a cara era coberta por um saco. Após um tempo na superficie eles tiravam o saco. (ESTADO DO RIO GRANDE DO SUL, 1997b, s.p.)

Manolo trabalhava das 8 às 19 horas usando, na maioria das vezes, "uma calça azularte [ou calção, como era mais comum no subsolo devido ao intenso calor], uma camisa riscada e uma alpargata de lona com sola de corda" (ESTADO DO RIO GRANDE DO SUL, 1997a, p. 2). Sérgio Sotelo, filho e neto de mineiros, salientou que, à época, não existiam equipamentos de segurança. Em relação às alpargatas, lembrou que elas eram "fabricadas na Argentina e no Brasil" e que "era o calçado do mineiro". Então, quando o mineiro ia fazer o "rancho", "comprava os mantimentos para a casa e, também, comprava um par de alpargatas que durava exatamente um mês - era este o calçado que ele usava para trabalhar no subsolo" (SOTELO, 2000, s.p.).

Jover registrou que a exploração do trabalhador nas minas de carvão ocorria "como se os operários fossem escravos". Afirmou que o trabalho no subsolo era "lamentável", e que além da exploração envolvia muita falta de segurança e de higiene. No subsolo, os mineiros tinham que conviver com o medo do desmoronamento e o barulho das máquinas, e também 
com o cheiro das cocheiras dos burros (até serem substituídos por locomotivas elétricas, provavelmente entre o final dos anos trinta e início da década de 1940), além do odor dos cubos. Os cubos eram recipientes de madeira, em formato de barril, em torno de $60 \mathrm{~cm}$ de altura, que serviam de vaso sanitário para os mineiros no subsolo. Ficavam em uma parte da galeria, geralmente separada por uma cortina de saco de estopa, e impermeabilizados com piche. No universo das minas, o "cubeiro" era o mineiro que tinha a função de recolher e recolocar os cubos nas galerias.

Em documento pesquisado por Clarice Speranza sobre esse assunto (depoimento de um fiscal de Higiene e Trabalho do Ministério do Trabalho, ouvido na Justiça em 1944), consta que, além de não haver lugar adequado para os mineiros evacuarem, havia vestígios dos dejetos em qualquer lugar no subsolo, local onde a maioria dos operários tinha que caminhar curvada devido à baixa altura do teto (SPERANZA, 2012, p. 53).

Em seu discurso de 1947, Jover destacou:

Nós, mineiros, trabalhamos a uma profundidade de 138 metros mais ou menos, e depois de estarmos embaixo do subsolo, caminhamos, muitas vezes, um quilometro ou dois pelo subsolo adentro. Nesse trabalho, nessa temperatura, o CADEM mantém a água nas seguintes condições: numa pipa de latão que enferruja uma semana após a sua primeira utilização. E nessa água muitas vezes - e sou obrigado a usar a expressão - quando se vai bebê-la, além da incômoda e vexatória posição de quatro pés a que se vê obrigado o mineiro em virtude da localização da torneira, depara-se com 2, 3 e até 4 ratos dentro dela. É isto que acontece nas minas de São Jerônimo. [...] Por outro lado o CADEM explora o mineiro de todas as maneiras. Existe nas minas de São Jerônimo um armazém, do qual, até bem pouco tempo atrás, um dos sócios era o próprio diretor do CADEM. Quer dizer, existe ainda o sistema do 'barracão', o sistema semi-feudal. Nesse armazém, vendem-se os artigos de primeira necessidade ao mineiro, mediante desconto em folha. [...] Esse armazém faz o seguinte: Hoje o mineiro adoece, não foi ao trabalho. Como o seu salário é mínimo e como, naturalmente, em virtude disso, não tem saldo a seu favor nesse 'barracão' para que possa suprir-se nos dias em que não trabalha, como conseqüência o 'barracão', sem levar em consideração os lucros já dado pelo mineiro a ele, assim como a garantia do pagamento posterior (uma vez que o pagamento é descontado em folha), nega-lhes os comestiveis, evitando, portanto, que os mineiros possam dar a sua contribuição ao país com o seu trabalho diário nas minas, pois, doente e sem recursos, difícil é o seu rápido restabelecimento. (ESTADO DO RIO GRANDE DO SUL, 1947, p. 405-407)

Muitas das críticas feitas por Manolo, em 1947, sobre a exploração do trabalho do mineiro pelo CADEM, também aparecem nas entrevistas realizadas com mineiros no ano de 2002, pelo antigo Centro de História Oral do Estado do RS. Questões relativas aos gastos dos operários com a pseudo "Cooperativa" (Armazém da Cia.), com ferramentas e instrumentos de trabalho, o sistema de controle da empresa, doenças e acidentes, e também os espaços de lazer são informações recorrentes no conjunto das entrevistas. ${ }^{4}$

O Armazém dos mineiros foi denunciado por Manolo, em 1946, como "regime do barracão":

Ainda impera naquela zona, praticamente, o regime do barracão. Existe um grande armazém que vende os gêneros de 3 a nos preços dos de 1 a e que até pouco tempo tinha como um dos seus sócios o Sr. Roberto Cardoso, o onipotente diretor-presidente das minas. Em virtude, porém, de uma campanha realizada pelo Sindicato, pelo menos aparentemente ele deixou de ser sócio do armazém. Este armazém é quem fornece aos trabalhadores, descontando as compras nas nossas folhas de pagamento. No dia em que o mineiro, por qualquer razão não comparece ao trabalho, imediatamente o arma-

4 Optou-se em não citar exemplos dessas fontes para não ultrapassar o limite de páginas deste artigo. As entrevistas podem ser localizadas no Arquivo Histórico do Rio Grande do Sul e, certamente, no Museu Estadual do Carvão. 
zém corta o fornecimento. É verdade que existem outras casas comerciais, mas só vendem a dinheiro e o mineiro raramente pode comprar à vista. (TELES, 1946, p. 1)

No campo da sociabilidade, procissões, festas religiosas, "domingueiras", carnaval, jogos e brincadeiras também integravam o cotidiano de Manolo no tempo das minas. Como escreveu em Evocação, "nem só de trabalho vivia o mineiro [...] "desde piá, participante, lembro nossa festa máxima, a Festa de Santa Bárbara! [...]" (TELES, 1993, s.p.).

Cornelia Eckert explicou que a devoção à Santa, em diversos países, "revela a crença na sua proteção contra acidentes de trabalho, incêndios, explosões, desmoronamentos, inundações, doenças e contra toda sorte de catástrofes" e, ao mesmo tempo, o "resguardo dos demônios e espíritos maléficos subterrâneos e seres sobrenaturais que aterrorizam, em todos os tempos, os trabalhadores das profundezas da terra". De acordo com a antropóloga, no estado do Rio Grande do Sul a festa à "padroeira dos mineiros" está vinculada ao começo da extração de carvão e à vinda de imigrantes da Europa que, no século XIX, se fixaram em Arroio dos Ratos atraídos pelo mercado de trabalho das minas. Para Eckert, nesse local formou-se "uma comunidade ocupacional, predominantemente católica, que reproduz nesta nova realidade uma tradição vivida pelos mineiros imigrantes europeus: a crença na Santa Bárbara". A festa também é uma "manifestação cultural-religiosa recolocada e reelaborada como um sistema de significados para o grupo local: comemora-se anualmente a festa da padroeira dos mineiros, igualmente padroeira da cidade" (ECKERT, 1992, p. 57).

Não se sabe se Manolo era devoto de Santa Bárbara e em que medida o teria sido. De acordo com o estudo de Cornelia Eckert, é possivel presumir que, enquanto mineiro, ele possa ter reproduzido práticas relacionadas ao sagrado no mundo do trabalho das minas. Conforme Eckert, a crença poderia "ser apreendida através de comportamentos individuais e coletivos".

Práticas individuais em relação ao sagrado podem ser avaliadas no cotidiano de trabalho, quando os mineiros por ocasião da descida à mina ou de seu retorno do subsolo, dirigem-se a imagens da Santa, dispostas na saída dos vestiários e na base do poço, com orações, pedidos, promessas, sinal da cruz, etc. A manifestação coletiva refere-se à comemoração anual da festa da Santa Padroeira. (ECKERT, 1992, p. 59)

É possivel, assim, que Manolo tenha apreendido algumas práticas relativas à crença em Santa Bárbara, pois esse universo não estava dissociado do cotidiano dos operários das minas de carvão, principalmente daqueles que enfrentavam os perigos e os medos de trabalhar no subsolo.

Em Arroio dos Ratos do Manolo mineiro, a festa de Santa Bárbara, realizada em 4 de dezembro, era a principal celebração dos operários, uma das datas mais esperadas pela comunidade. Com a aproximação desse dia, aumentavam os momentos de sociabilidade dos mineiros, pois encontros, reuniões, jantares, missas e novenas antecipavam a procissão do dia 4, seguida de missa e muita festa.

Enquanto o Brasil entrava na ditadura do Estado Novo, Manolo, aos dezessete anos, aproximadamente, preparava-se para o festejo de Santa Bárbara. Na segunda metade da década de 1930, as ideias comunistas atingiriam o coração do jovem Manolo. Politicamente, o clima ficava cada vez mais tenso nas minas de São Jerônimo.

Jover, certamente, teve contato com as ideias anarquistas, porque elas estavam presentes nas minas de carvão desde o final do século XIX. No acervo do Museu Estadual do Carvão, por exemplo, há o primeiro registro de greve de operários das minas, em um relatório da Companhia Estrada de Ferro e Minas de São 
Jerônimo, de 1895. Conforme o documento, a greve foi deflagrada em um 1o de maio, liderada por imigrantes europeus que trabalhavam nas minas e que se manifestaram utilizando "bandeiras encarnadas e manifestações anarquistas" (RELATÓRIO..., 1895). Todavia, o que ficaria evidente é que na segunda metade da década de 1930 o mineiro viraria comunista.

Fontes orais, como as entrevistas realizadas para este texto com a esposa, com a filha e com a enteada de Jover, informam que o espanhol Jeronymo realizava reuniões clandestinas em sua casa e que, por isso, havia denúncias contra ele.

E o pai dele [de Jover Teles] também fazia uma arrecadação de dinheiro aqui e mandava pra Espanha, não sei pra quem... Uma entidade na Espanha. E aquela vez ele comprou aquele livro do... Eu não sei quem, não me lembro o nome... E houve uma denúncia que eles faziam uma reunião na casa do pai dele e veio a polícia e prendeu todo mundo. Prendeu o pai e prendeu todos os filhos. Foi dessa vez que eles foram para uma ilha... Uma ilha que tem perto de Porto Alegre. Ele teve não sei quanto tempo preso. Depois soltaram eles. Eu sei que naquela época o meu pai que também era mineiro e era comandante deles, todos os espanhóis de Arroio dos Ratos se envolveram na defesa deles e no fim soltaram, não acharam prova nenhuma.

Autor: Teve mobilização dos mineiros para soltar eles?

Entrevistada: Teve. Meu pai fez parte. (GONÇALVES, 2011, s.p.)

A informação sobre a prisão de Jover Teles ainda jovem, nas minas de Carvão, confere com o que foi exposto no periódico comunista Libertação, em matéria publicada no período de início das campanhas eleitorais de 1945. De acordo com o Libertação, em 1937 Jover "foi preso pela polícia fascista" e "com seu pai e mais dois irmãos esteve na Ilha do Paiva, durante cinqüenta dias", sendo solto graças à "sua profunda ligação com a massa" que "impediu” sua condenação, e "permitiu" a "Manoel Jover Telles voltar para o fundo da mina e para a luta ao lado dos milhares de mineiros da colméia humana de São Jerônimo" (QUEM..., 1945, p. 6). É evidente que a matéria publicada está relacionada ao contexto da campanha eleitoral de 1945, no qual Jover Teles foi lançado candidato a deputado federal. Talvez por isso o peso colocado no texto, que salienta "a profunda ligação" de Jover "com a massa", deva ser relativizado. Mas, independentemente, o que nos interessa nesse momento é a questão da prisão de Manolo naquele contexto. A filha de dona Isabel, Eluiza Maio, que conviveu muito com Manolo no final de sua vida, ao se lembrar de uma das histórias que ele contava, destaca:

Um dos fatos que chamou muita atenção foi que ele [Manolo] contou que quando tinha dezesseis ou dezessete anos, ele ganhou a primeira fatiota dele para ir numa festa. Era uma festa importante em Arroio dos Ratos, a festa de Santa Bárbara. Lá ele ia inclusive encontrar uma menina que ele tava interessado, mas ele não chegou a ir nesta festa porque o pai dele foi preso e levaram ele junto. E ele acabou ficando preso no meio do rio [Guaíba], onde tinha um presídio - eu não me lembro o nome. Ele disse que não tinha nada a ver, que ele foi preso inocentemente, que ele estava ali para ir numa festa... E acabou com a fatiota dele, no meio do rio, naquela prisão que tinha ali em Guaíba. $\mathrm{Na}$ prisão ele conheceu líderes da filosofia de vida que ele adotou, o socialismo. Lá ele disse que tinha presos políticos. Ali foi a escola dele. Foi preso inocentemente e a escola dele foi dentro do presídio onde havia presos políticos. (MAIO, 2011, s.p.)

Dona Isabel também salienta que foi depois dessa primeira prisão que "Manolo começou a ferver a cabeça" e "começou a mostrar as unhas" e, mais tarde, "colocaram ele como candidato" (GONÇALVES, 2011, s.p.). Na entrevista concedida para o presente texto, ela lembrou que o livro que o pai de Jover Teles adquiriu antes da prisão, em 1937, era vendido nas 
minas por mascates ("Os mascates vendiam ali. E ele viu aquele livro e comprou", conta ela). Desse modo, também não se pode descartar a possibilidade de Manolo ter tido contato com as ideias socialistas antes mesmo da prisão.

De qualquer forma, conforme salientaram Isabel e Eluiza, foi depois da prisão, onde the estragaram a fatiota, e onde também conviveu com outros presos políticos, que ficaria mais evidente que o mineiro havia se tornado comunista. Mas essa já é outra história.

\section{Considerações finais}

Como observou Vavy Pacheco Borges, em relação à biografia de Gabrielle Brune-Sieler, ao se pensar sobre um sujeito pensa-se nas normas, nas práticas, nas regras da sociedade e da família em que ele está inserido (BORGES, 2004). Isto porque "a razão mais evidente para se ler uma biografia é saber sobre uma pessoa, mas também sobre a época, sobre a sociedade em que ela viveu" (BORGES, 2006, p. 215). Nesse sentido, o que se logrou até aqui foi elaborar uma reflexão que sistematizasse algumas características sobre o trabalho nas minas de carvão de Arroio dos Ratos, na e a partir da trajetória operária de Manoel Jover Teles, sem, contudo, limitar o exercício à escrita biográfica como um "fio condutor", pois isso representaria perder o foco no indivíduo. Dessa maneira, as questões teórico-metodológicas estiveram pautadas em uma abordagem biográfica que buscou exercitar a articulação de uma história-narrativa com uma história-problema, pois se compreende que uma "biografia histórica é antes de tudo história", e que "ela precisa se pautar pelos procedimentos de pesquisa e pela própria narrativa deste campo de conhecimento, que se propõe a explicar e/ou compreender o passado" (SCHMIDT, 2011, s.p.).

Buscando "os fios e os rastros" de e sobre Manoel Jover Teles, foram analisados alguns contextos de sua trajetória operária nas décadas de 1930 e 1940 que, de acerta forma, ficaram eclipsadas em virtude de se tratar de um homem sobre o qual incide uma "memória da traição" vinculada ao episódio do Massacre da Lapa. Uma memória que, como qualquer outra, é uma reconstrução continuamente atualizada do passado e que, por se manifestar também de forma retórica e estar associada a estratégias culturais e políticas de gestão da memória de um grupo, silenciou diferentes facetas e trajetórias de Manolo, colocando em evidência apenas a efigie estigmatizadora (SILVEIRA, 2013).

Neste artigo, uma das facetas da trajetória de Manolo saiu do ostracismo e ganhou evidência à luz de uma biografia histórica. Manoel Jover Teles foi operário, mineiro, furador, cartucheiro. Das minas, ganhou o mundo, entrou para a História. A partir da década de 1940 foi destacado membro do PCB e um operário que se intelectualizou. Foi um marxista-leninista motivado, como muitos outros militantes de seu tempo, a realizar uma Revolução no Brasil de outrora. Na condição de deputado estadual, em 1947, destacou-se como um legítimo representante da classe operária. Todavia, como vimos, para compreender parte dessa trajetória foi preciso estar atento às operações de uma escrita da história que, não se limitando à narração e classificação das fontes, considerou a relação entre o lugar do discurso, os procedimentos de análise e sua construção (CERTEAU, 2008), sem ignorar os lugares sociais/institucionais nos quais Manoel Jover Teles foi produzido e pelos quais foi igualmente influenciado.

\section{Referências}

AS ELEIÇÕES no Rio Grande do Sul. Porto Alegre: Edições Sintese, s.d.

BORGES, Vavy Pacheco. Desafios da Memória e da biografia: Gabrielle Brune-Sieler, uma vida (1874- 
1940). In: BRESCIANI, Stella; NAXARA, Márcia. (Orgs.). Memória e (res)sentimento: indagações sobre uma questão sensível. 2. ed. Campinas, SP: Editora da Unicamp, 2004. p. 283-308.

Grandezas e misérias da biografia. In: PINSKY, Carla Bessanezi. (Org.). Fontes históricas. 2. ed. São Paulo: Contexto, 2006. p. 203-233.

CERTEAU, Michel. A escrita da história. 2. ed. Rio de Janeiro: Forense Universitária, 2008.

CIOCCARI, Marta. Ecos do subterrâneo: estudo antropológico do cotidiano e memória da comunidade de mineiros de carvão de Minas do Leão - RS. 2004. Dissertação (Mestrado em Antropologia Social) - IFCH/Programa de Pós-Graduação em Antropologia Social, Universidade Federal do Rio Grande do Sul, Porto Alegre, 2004.

ECKERT, Cornelia. Os homens da mina - um estudo das condições de vida e representações dos mineiros de carvão em Charqueadas/RS. 1985. Dissertação (Mestrado em Antropologia) - Programa de Pós-Graduação em Antropologia, Sociologia e Ciência Política, Universidade Federal do Rio Grande do Sul, Porto Alegre, 1985.

ECKERT, Cornelia. Passado e presente de devoção na padroeira dos mineiros de carvão. Estudo da festa de Santa Bárbara no Brasil e na França. In: TEIXEIRA, Sérgio Alves; ORO, Ari Pedro. (Orgs.). Brasil e França: ensaios de antropologia social. Porto Alegre: Editora da UFRGS, 1992. p. 55-77.

EGEA BRUNO, Pedro Ma. Conyuctura minera y clase obrera em Linares (1882-1886). Revista de Historia Contemporánea, n. 5, p. 137-156, 1991.

ESTADO DO RIO GRANDE DO SUL. Ação de acidente de trabalho no 2885/1929 da 2a Comarca do Superior Tribunal do Estado do Rio Grande do Sul - APERS. Autor: Carlos Wietzorecki; Ré: Companhia Estrada de Ferro e Minas de São Jerônimo. Arquivo Público do Estado do Rio Grande do Sul, Cartório Cível e criminal, maço 54, est.05, São Jerônimo, 1929.

ESTADO DO RIO GRANDE DO SUL. ANAIS da Assembleia Legislativa do Estado do Rio Grande do Sul, Volume IX, Setembro de 1947, 48 a Sessão, em 16 de setembro de 1947.
ESTADO DO RIO GRANDE DO SUL. Museu Estadual do Carvão. Questionário respondido por Manoel Jover Teles em 12/09/1997. Pasta "Entrevista - mineiros", acervo do Museu Estadual do Carvão, Arroio dos Ratos, 1997a.

ESTADO DO RIO GRANDE DO SUL. Museu Estadual do Carvão. Questionário respondido por ex-mineiro. Pasta "Entrevista - mineiros", acervo do Museu Estadual do Carvão, Arroio dos Ratos, 1997b.

ESTADO DO RIO GRANDE DO SUL. Processo 1.734 de 1942. Ação de Acidente de Trabalho. Tribunal de apelação do estado do Rio Grande do Sul, Acervo de processos judiciais do Arquivo Judicial Centralizado de Porto Alegre. Autor: Leon Jover Telles; Ré: Companhia Estrada de Ferro e Minas de São Jerônimo, 1942.

ESTADO DO RIO GRANDE DO SUL. Processo 118 de 1946. Acervo do Memorial da Justiça do Trabalho (Junta de São Jerônimo). Reclamante: Braulio Jover Telles; Reclamado: Cia Estrada de Ferro e Minas São Jerônimo. Porto Alegre, Memorial da Justiça do Trabalho, Caixa 5, 1946.

GINZBURG, Carlo. 0 fio e os rastros: verdadeiro, falso, fictício. São Paulo: Cia. das Letras, 2007.

GOMES, Paulo Junqueira. Sobre cargos e funções nas minas de carvão de São Jerônimo. Arroio dos Ratos, 04 de junho de 2013, entrevista concedida a Éder da Silva Silveira.

GONÇALVES, Isabel. Sobre Manoel Jover Teles. Florianópolis, SC., 10 de fevereiro de 2011. Entrevista concedia a Éder da Silva Silveira.

KLOVAN, Felipe Figueiró. Sob o fardo do Ouro Negro: as experiências de exploração e resistência dos mineiros de carvão do Rio Grande do Sul na década de 1930. 2014. 233 f. Dissertação (Mestrado) - Programa de Pós-Graduação em História, Universidade Federal do Rio Grande do Sul, Porto Alegre, 2014.

LE GOFF, Jacques. Comment écrire une biographie historique aujourd'hui? Le Débat, n. 54, p. 48-53, mar./avr. 1989.

LIMA, Iracema Coelho. História de vida de Manoel Jover Teles e memórias de família. Entrevista concedida a Éder da Silva Silveira. Arroio dos Ratos, 07-05-2009. 
MAIO, Eluiza. Sobre Manoel Jover Teles. Florianópolis, SC., 10 de fevereiro de 2011. Entrevista concedida a Éder da Silva Silveira.

MUNICÍPIO de Cerquilho completa 64 anos de desenvolvimento. Jornal Nossa Folha, 09 de abril de 2013, s.p. Disponivel em: <http://www. jornalnossafolha.com.br/more-about-joomla/29home/1615-municipio-de-cerquilho-completa-64anos-de-desenvolvimento.html>. Acesso em: $14 \mathrm{fev}$. 2013.

QUEM são os candidatos comunistas pelo Rio Grande do Sul. Libertação, 17-11-1945, p. 3-6. Acervo do setor de pesquisa e imprensa do Museu de Comunicação Social Hipólito José da Costa.

RELATÓRIO da Companhia Estrada de Ferro e Minas de São Jerônimo. Rio de Janeiro: Oficinas do Jornal do Brasil, 1895.

SCHMIDT, Benito Bisso. Relações perigosas: História e biografia. Registro de palestra proferida no "Encontros Transdisciplinares (I). (AUTO)BIOGRAFIA(S)". Porto Alegre, Universidade Federal do Rio Grande do Sul, Sala Pantheon do IFCH/UFRGS - Campus do Vale, 6 de junho de 2011.

SILVA, Cristina Ennes. Nas profundezas da terra: um estudo sobre a Região Carbonífera do Rio Grande do Sul (1883/1945). 2007. 392 f. Tese (Doutorado em História) - Programa de Pós-Graduação em História, Pontifícia Universidade Católica do Rio Grande do Sul, Porto Alegre, 2007.

SILVEIRA, Éder da Silva. Ensaios de pesquisa de campo em Arroio dos Ratos. Texto apresentado em um seminário de Antropologia na Universidade Luterana do Brasil, em julho de 2000.

SILVEIRA, Éder da Silva. Representações sobre o trabalho nas minas de carvão de Arroio dos Ratos. In: ENCONTRO NACIONAL DE HISTÓRIA ORAL - Tes- temunhos e conhecimento, 9., 2008, São Leopoldo. Anais... São Leopoldo, RS: Unisinos, 2008. p. 1-12.

SILVEIRA, Éder da Silva. Além da traição: Manoel Jover Teles e o comunismo no Brasil do Século XX. 2013. 307 f. Tese (Doutorado em História) - Programa de Pós-Graduação em História, Universidade do Rio dos Sinos - Unisinos, São Leopoldo, RS, 2013.

SORIANO, Ignacio C.; MADRID, Francisco. Antología documental del anarquismo español. VI. Bibliografía e historiografia. 4. ed., s.n., out. 2010.

SOTELO, Sérgio. Memórias de família sobre o cotidiano dos mineiros e a enchente de 1936. Arroio dos Ratos, maio de 2000. Entrevista concedida a Éder da Silva Silveira.

SPERANZA, Clarice Gontarski. Cavando direitos. As leis trabalhistas e os conflitos entre trabalhadores e patrões nas minas do Rio Grande do Sul nos anos 40 e 50. 2012. 272 f. Tese (Doutorado em História) IFCH/PPGH, Universidade Federal do Rio Grande do Sul, Porto Alegre, 2012.

SULZBACH, Ervino Lothar. Perfil de um minerador. Arroio dos Ratos: PBS, 1989.

TELES, Manoel Jover [Manolo]. Arroio da esperança. Arroio dos Ratos: Gráfica PBS, 1993.

TELES, Manoel Jover [Manolo]. São Jerônimo é um inferno de carvão. Tribuna Popular, 18 de janeiro de 1946.

WOODCOCK, George. Anarquismo: introdução histórica. In: . (Org.). Os grandes escritos anarquistas. Porto Alegre: LP\&M, 1981. p. 11-52.

Recebido em: 30.12 .2017 Aprovado em: 30.05.2018

Éder da Silva Silveira é professor pesquisador do Programa de Pós-Graduação em Educação e do Departamento de História e Geografia da Universidade de Santa Cruz do Sul - Unisc. É líder do Grupo de pesquisa: História, Memórias e Narrativas em Educação - CNPq. Doutor em História pela Universidade do Vale do Rio dos Sinos - Unisinos; mestre e pós-doutor em Educação pela PUC-RS. e-mail: eders@unisc.br 